\title{
Osteogenesis Imperfecta Type V: A Report of Two Filipino Families and Review of Literature
}

\author{
Melissa Mae P. Baluyot, ${ }^{1}$ Barbra Charina V. Cavan² and Maria Melanie Liberty B. Alcausin ${ }^{1,3}$ \\ ${ }^{1}$ Institute of Human Genetics, National Institutes of Health, University of the Philippines Manila \\ ${ }^{2}$ Department of Pediatrics, Cebu Doctors' University Hospital, Osmeña Blvd., Cebu City \\ ${ }^{3}$ Department of Pediatrics, College of Medicine and Philippine General Hospital, University of the Philippines Manila
}

\begin{abstract}
Osteogenesis imperfecta (OI) type $\mathrm{V}$ is a distinct Ol phenotype that has recently been described. Patients with this phenotype present characteristically with interosseous membrane calcification and hyperplastic callus formation. We present the clinical and radiographic characteristics of two Filipino families diagnosed to have OI type $\mathrm{V}$. Through this review of cases, we aim to educate healthcare providers by highlighting salient clinical and radiographic features to aid in the recognition of this specific Ol phenotype, difficulties in diagnosis, current practices in management and fracture prevention, and issues in genetic counseling.
\end{abstract}

Key Words: Osteogenesis imperfecta Type V, bone fragility, pamidronate, Filipino

\section{Introduction}

Osteogenesis imperfecta is a genetic disorder characterized by bone fragility, manifested as fractures after no or minimal trauma, with subsequent skeletal deformities. It has been classically categorized by Sillence et al into four main clinical phenotypes. ${ }^{1-3}$ More recently, as more molecular and histological studies were made, other distinct groups have been described and the expanded classification includes at least 9 other phenotypes in addition to the classical OI types I - IV. ${ }^{2}$ Nomenclature revisions have accordingly seen the numbers of $\mathrm{OI}$ types being increased up to OI type XIV. ${ }^{4}$ However, many authors believe that this might become a very unwieldy numerical system. This is confusing in clinical practice since the newly added OI types, result in an OI classification in which the types are not mutually exclusive. A recommendation has been made to

Presented as a poster at the 6th International Conference on Birth Defects and Disabilities in the Developing World, November 2013, Mactan, Cebu City, Philippines.

Corresponding author: Maria Melanie Liberty B. Alcausin, MD Institute of Human Genetics

National Institutes of Health

University of the Philippines Manila

Department of Pediatrics

College of Medicine and Philippine General Hospital

University of the Philippines Manila

Tel: +6325257459

Email: mmlbalcausin@post.upm.edu.ph cease using the numerical nomenclature and instead go back to a descriptive grouping of the syndromes. ${ }^{1}$

Patients with OI type I have a mild non-deforming presentation, with normal height or mild short stature, blue sclerae, with or without dentinogenesis imperfecta, and early onset hearing loss. ${ }^{1,2,5}$ OI type II, on the other hand, is most often lethal in the perinatal period; patients have minimal cranial mineralization, beaded or broad ribs, with compressed femurs, marked long bone malformation, platyspondyly and dark blue/gray sclera. ${ }^{1,2,5}$ Patients with OI type III have the most severe form compatible with life, with progressive limb and spine deformities. They also have very short stature, grayish sclerae or initially bluish sclerae which become progressively less blue with age and dentinogenesis imperfect.1,2,5 Typically, patients with moderate to severe phenotypes who did not fit into one of the 3 categories were lumped into OI type IV. ${ }^{1}$ Patients with OI type IV present with recurrent fractures, osteoporosis and variable degrees of deformity of long bones and spine but normal sclerae with or without dentinogenesis imperfect. ${ }^{1}$

Most of the newer forms of OI are inherited in an autosomal recessive manner except for type $\mathrm{V}$ which is inherited in an autosomal dominant pattern similar to types I - IV. ${ }^{2}$ Ninety percent of patients with types I - IV phenotype have mutations in the COL1A1/ COL1A2 gene whereas mutations in the interferon-induced transmembrane protein-5 (IFITM5) have been reported in type $\mathrm{V} .{ }^{6-8}$ Mutations in several other genes CRTAP, LEPRE1, FKBP10, PPIB, SP7/osterix (OSX), SERPINF1, SERPINH1, TMEM38B, and BMP1 have been reported in the autosomal recessive types. ${ }^{1,2} \mathrm{X}$-linked inheritance of OI has also been described and loss-of-function mutations in PLS3 encoding plastin-3 were discovered recently.1,9

OI affects an estimated 1 in 10, 000 people without gender or racial predilection. ${ }^{10}$ In the Philippines, exact prevalence is unknown. However, in the Philippine General Hospital (PGH), we have seen at least 60 persons affected with OI since the opening of the Genetics Clinic in 1991 (Institute of Human Genetics, unpublished data). Most of these patients are categorized using the classic Sillence classification. Preliminary results of an ongoing study on the molecular characterization of some of our patients have 
shown 5 patients with mutations in COL1A1. Two of these are novel mutations (Alcausin et al, unpublished).

We have recently diagnosed OI type $\mathrm{V}$ in two Filipino families, three children and two adults. Two of the children were seen at PGH while the other child was seen at a private genetics clinic in Cebu City. The adults described in this series are parents of the children.

\section{Materials and Methods}

After obtaining consent for publication, the clinical and radiographic features of two Filipino families, three children and two adults, were collated and described in detail. A review of literature has been done and is presented.

\section{Results}

\section{The Patients}

\section{Family A}

Two of our patients are sisters born to a nonconsanguineous couple of Filipino descent. The 26-year-old mother is healthy while the father, although not physically examined in the clinic, is similarly affected based on history and photos provided.

The older of the two siblings, Patient 1, is six years old, born term via spontaneous vaginal delivery with an unremarkable prenatal history. At birth, she was noted to have bilateral elbow deformity but otherwise well. She fractured her right femur at two years of age after having accidentally tripped. Surgical management was done. At four years, she fractured her right leg after trying to stand. At this time, only casting was done. Due to the recurrent fractures, she was brought to a tertiary hospital where she was seen by a geneticist. The patient had normal intelligence, non-dysmorphic facial features, normal-looking teeth but with multiple dental caries, mild pectus excavatum, bowed forearms with reduced supination/pronation. She had bowing of the long bones of the lower extremities, with palpable protrusion of the radial heads and heads of the fibula. She is able to stand with support but has difficulty ambulating (Figures 1a-e).

Patient 2, the younger sibling, is four years old. She was also born term via spontaneous vaginal delivery following a normal pregnancy. At birth, she was also noted to have bilateral elbow deformity like her sister. She only had one documented fracture (right leg) at three years of age but noted with progressive bowing of the lower extremities. She has normal intelligence, non-dysmorphic facial features, normal-looking teeth, bowed forearms with reduced supination/pronation and bilateral radial head dislocation, and bowing deformity on the lower extremities, more prominent on the right, leading to problems with ambulation (Figures 2a-g).
The sisters have been receiving intravenous bisphosphonate therapy for less than a year with clinical and radiologic improvement (Figures $1 \mathrm{f}$ and 2f). No new fracture has been reported. Improvement in stamina and less body pains were noted since start of treatment.
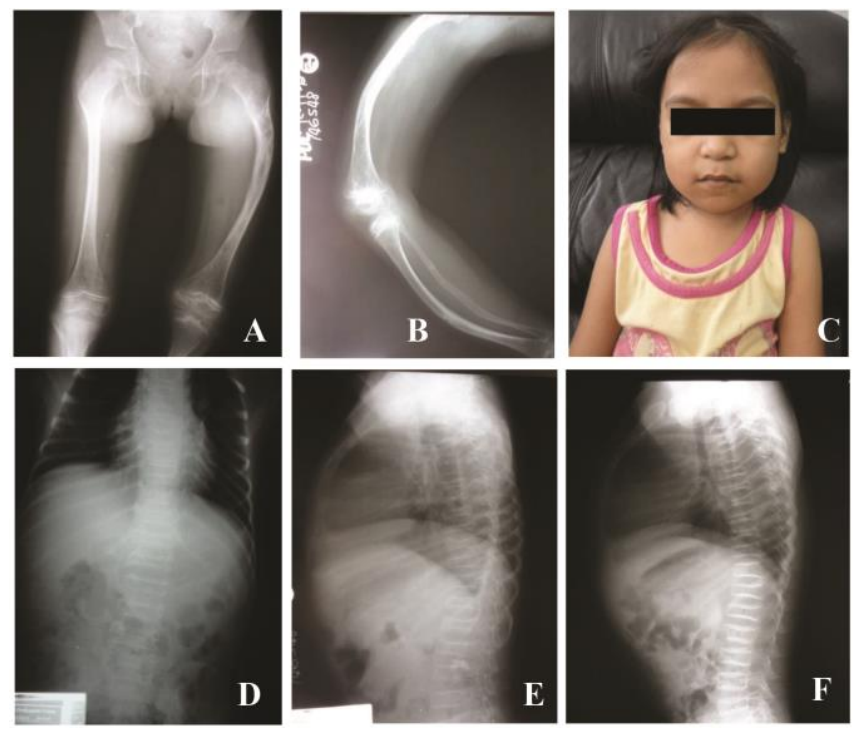

Figure 1. (Patient JS) a-b. Evident osteopenia and bowing of the left femur and long bones of the upper extremities. c. Patient JS d-e. Baseline x-ray of the spine showing vertebral compression fractures. f. Improvement in the shape and height after 8 months of pamidronate therapy. Photographs are published with consent.
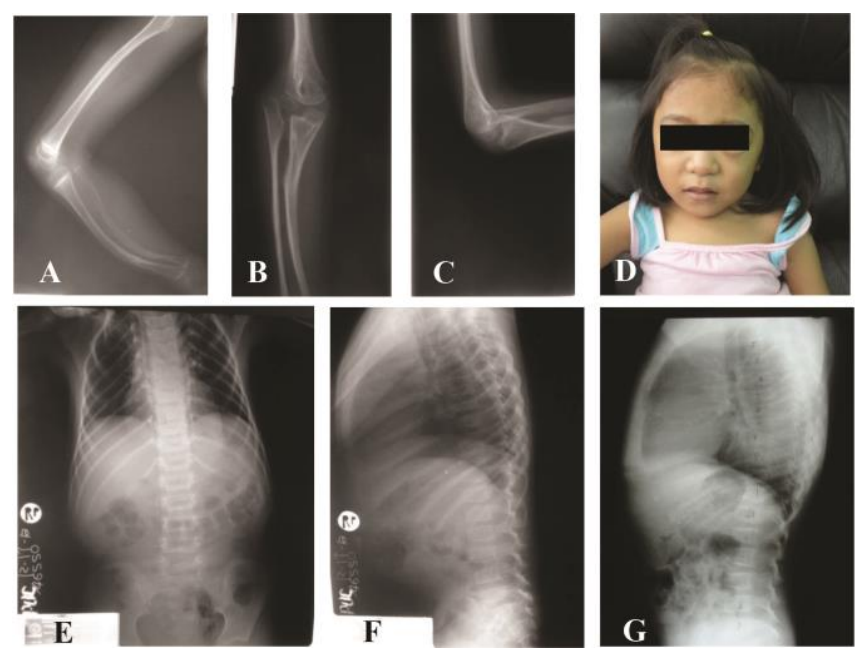

Figure 2. (Patient CS). a-c. Osteopenia and bowing of the long bones of the extremities with radial head dislocation. $\mathbf{d}$. Patient CS e-f. AP lateral spone x-ray prior to starting treatment. g. Lateral spine $\mathrm{x}$-ray 8 months from start of Pamidronate therapy showing improved vertebral shape and height. Photographs are published with consent. 
Patient 3 is the father of Patients 1 and 2. He was also born with bilateral elbow deformity and has had several fractures which resulted in severe bone deformities. In his 20s, he was brought for consultation at a tertiary hospital for an acutely developing thigh mass. The primary impression was a bone malignancy due to the x-ray findings. Due to financial constraints, no further treatment was sought.

Patient 3 is currently 31 years of age and is wheel-chair bound (Figure 3a). Photograph provided shows prominent radial heads and severe bone deformities especially of the lower extremities (Figure 3b). He was unable to attend the clinic due to financial constraints. $\mathrm{He}$ is currently unemployed and is assisted with his activities of daily living. Radiographs of his upper forearms show short and deformed left radius and ulna with loss of the medial margins of the left radius.
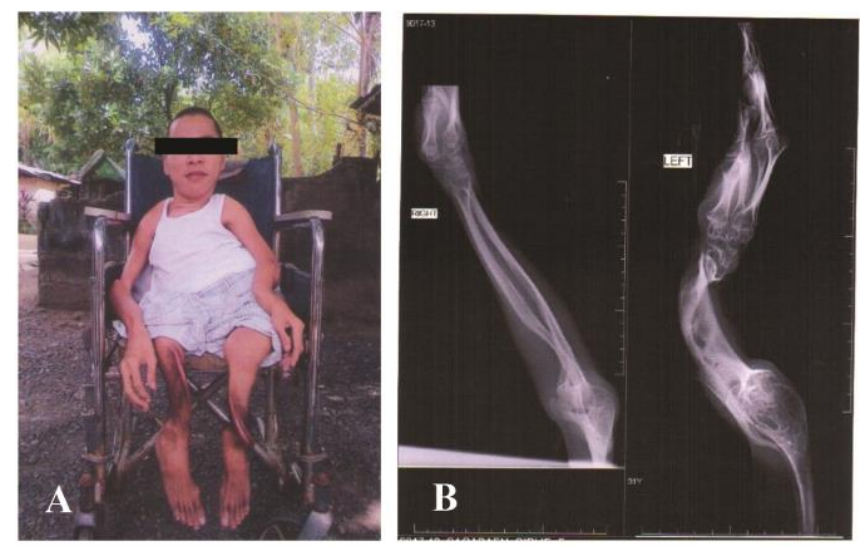

Figure 3. a. Severe bone deformities in both upper and lower extremities. b. Short and deformed left radius and ulna.

\section{Family B}

Patient 4 , is a four-year-old Filipino boy who is the only child of a 26-year-old mother and 20-year-old father. His prenatal and perinatal courses were unremarkable. His growth and developmental milestones were at par for age. At two years of age, he fractured his right arm after minimal trauma. This healed with residual deformity. He subsequently had left clavicular fracture at age three years and left lower leg fracture at four years which led to more orthopedic consults and eventually, a genetics referral, At the time of examination, weight was at $50^{\text {th }}$ percentile while height and head circumference were between the $25^{\text {th }}$ and $50^{\text {th }}$ percentile. There was no facial dysmorphism and no dentinogenesis imperfecta observed. He had prominent radial heads on his elbows and had limited pronation/supination (Figures 4a-b). Heads of the fibula were also prominent (Figures $4 \mathrm{c}-\mathrm{d}$ ).

Patient 5 is Patient 4 's mother. She has bilateral congenital elbow deformities, with note of prominence of the radial heads. She also has limited pronation and supination of the forearms. Additionally, she is unable to open the right hand completely. This has been noted since she was a month old but no medical consultations were done. She does not recall having had fractures, but does experience occasional back pain (especially after long periods of standing). She presently works as a teacher. She was able to deliver CF via normal vaginal delivery with no complications. She is $145 \mathrm{~cm}$ in height, has no long bone deformities and no difficulty of ambulation. She has normal teeth and she has bony prominences on the lateral side of her knees. Both mother and son have not received pamidronate therapy yet.

Patients 4 and 5 were found to have a heterozygous c.$14 \mathrm{C}>\mathrm{T}$ mutation in the IFITM5 gene.

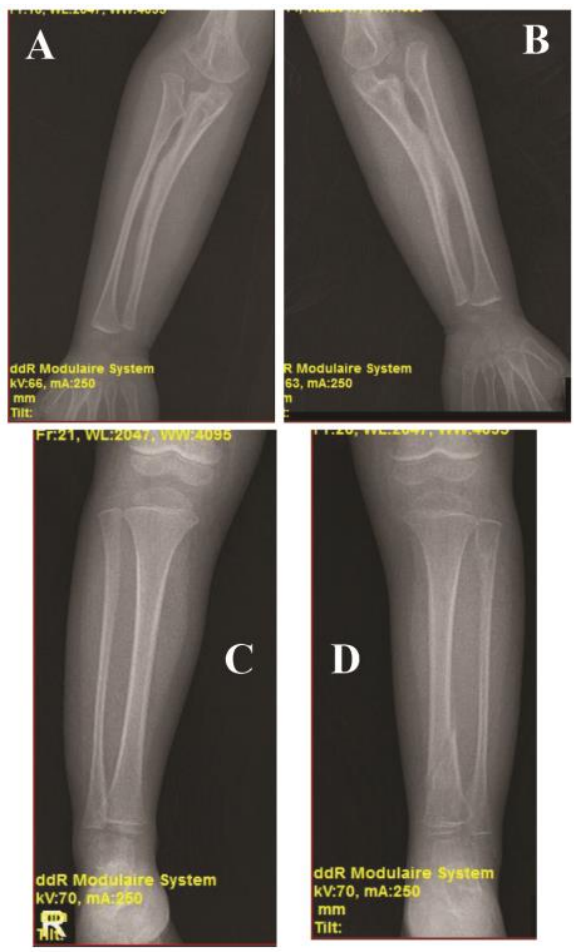

Figure 4. (Patient CF). a-b. There is dysplasia of the proximal ulna and radial head of both forearms with slight subluxation of the left radial head. Beginning interosseous calcification is evident at the middle portion of the left forearm. c-d. There is generalized thinning of the cortices of the long bones and a note of an oblique fracture seen at the distal left tibia with callus formation and periosteal reaction around the fractured site. There is also note of cortical irregularity at the proximal left fibula.

\section{Discussion}

\section{Salient Clinical and Radiographic Features}

OI type $\mathrm{V}$ was first proposed as a distinct entity by Dr. Kazimierz Kozlowski in the 1970s (Sillence, personal communication, March 20, 2014). Dr. Glorieux et al on the other hand described its histomorphometric characteristics 
and named it as a distinct phenotype in $1997 . .^{5}$ It is differentiated from other OI types by the presence of interosseous membrane calcification and hyperplastic callus formation typically noted following fracture healing. ${ }^{11}$

Interosseous membrane calcification of the forearm, together with its associated limitation in supination/pronation, is the most consistent reported clinical/radiographic feature in almost all cases published in literature. ${ }^{1,5,8,11-12}$ Although typically called "interosseous membrane calcification", some authors prefer to use the descriptive term "cortical thickening/excrescence of interosseous margin" on the radius-ulna diaphyses since it has not been distinguished whether this finding signifies calcification of proper interosseous membrane or indicates proliferation and irregular thickening of cortices and periosteum along the interosseous margins of the radius and ulna. ${ }^{13}$

Kim et al have noted that exosteal protuberance and cortical thickening along the interosseous margin of the ulna was one of the earliest radiographic findings, and this was observed as early as 4 months of age. ${ }^{13}$ This interosseous cortical thickening seemed to progress with age as seen in follow-up radiographs in some of their patients. Interosseous calcification has been appreciated along the interosseous margins of the tibia and fibula as well. This primarily involved the distal tibia and fibula near the ankle joint in patients over 20 years of age. ${ }^{13}$

Among the children, only CF had interosseous membrane calcification on x-ray. Although the x-ray's of JS and CS did not show this characteristic radiographic finding, this was observed in the x-ray of their father.

The development of a hyperplastic callus during the healing of long bone fractures is characteristic of OI type V. ${ }^{14}$ The radiographic finding of such often supports or practically clinches the diagnosis although this is found only in $65 \%$ of cases at most. ${ }^{12,15}$ This exaggerated callus formation mimics the appearance of osteosarcoma ${ }^{1,5,8}$ and this partly explains why some patients may be initially misdiagnosed such as what happened to JS and CS' father. Hyperplastic callus formation is most common in the femur while other long bones are less involved. It is described to be self-limiting and it commonly decreases progressively in size over time. Not all patients however develop complete resolution. Some were reported to have residual calcified mass and/or exuberant cortical thickening. ${ }^{13}$

Patients with OI type V have not been usually described as having facial dysmorphisms. This was observed in our series of patients. However, Balasubramanian et al reported a distinct facial gestalt in their cohort of patients which included a broad forehead, a short up-turned nose, a small mouth with a thin upper lip, a prominent chin and grayishblue sclera. ${ }^{2}$

Dental findings in patients with OI type $\mathrm{V}$ are characteristically described as normal., ${ }^{2} 16$ However, Kim et al have shown a high incidence of dental anomalies in their group of patients. ${ }^{13}$ The findings included missing permanent dentition, ectopic eruption, and short roots of the molar teeth. ${ }^{13}$ Grossly, both dentition of the siblings are white but with multiple dental caries, the third patient on the other hand did not have abnormal dental findings at the time of clinic visit.

\section{Genetics and Molecular Basis of OI type V}

The discovery of the causative gene responsible for OI type $\mathrm{V}$ has been facilitated recently through whole exome sequencing and genome-wide linkage analysis.7,8 The identified gene, IFITM5, is also known by its alternative and probably more appropriate name bone-restricted interferoninduced transmembrane protein-like protein or BRIL. ${ }^{15}$ Studies have shown that BRIL was only expressed in osseous tissues, localized particularly in active osteoblasts in the growth plate and on periosteal surfaces. ${ }^{15,17}$ It was also observed to be present in both flat and long bones throughout life, but expression was noticeably decreased in aged bones, probably due to reduced number of osteoblasts in such bones. ${ }^{15,17}$ However despite additional studies, the mechanism of action still remains elusive to researchers. Hanagata et al's research demonstrated that a BRIL knockout mouse had a minor reduction in bone length during prenatal development but had no adult skeletal abnormalities. ${ }^{18}$ Other unpublished researches have also observed that IfitmDel mice (the whole IFITM locus is deleted) did not show skeletal defects, and BRIL knockout mouse did not have a skeletal phenotype. ${ }^{15}$ An alternative hypothesis to this is that the underlying mutation in OI type $\mathrm{V}$ results in a gain-of-function. ${ }^{15}$ This may be supported by the in vitro finding that overexpression of BRIL in osteoblasts has resulted in increased mineralization. ${ }^{17}$ Additional studies in transgenic mice overexpressing BRIL or knock-in mice expressing the human mutation are needed to validate this claim. ${ }^{15}$

Molecular studies have not been done for the first family. The second family was fortunate to have been included in a molecular study where Sanger sequencing of IFITM5 showed that all of the nine study participants with OI type $\mathrm{V}$ were heterozygous for the autosomal dominant c.$14 \mathrm{C}>\mathrm{T}$ mutation. In the same study, it was shown that individuals with identical IFITM5 mutations have highly variable phenotypic expression, even within the same family. ${ }^{19}$

\section{Management and Fracture Prevention}

As in other types of OI, the management of OI type $\mathrm{V}$ involves prevention of fractures, development of optimal bone mass and muscle strength and enhancement of independent mobility. ${ }^{20,21}$ The introduction of intravenous bisphosphonate therapy in the 1990s has provided a paradigm shift in the care of persons with $\mathrm{OI}^{22}$ a condition 
that was probably initially believed to be hopeless. Various published literature have shown that bisphosphonate treatment in OI provided several advantages such as increase in bone mass, decreased fracture rate, improved growth, muscle strength and mobility. ${ }^{23-25}$ Reports on the use of pamidronate in infants have demonstrated improved vertebral shape in addition to increase bone mass and decreased fracture rate. ${ }^{26-28}$ A local study has similarly published that patients on intravenous pamidronate therapy had a decrease in fracture rate, improvement in vertebral shape, improved mobility, decreased sweating and less bone pain. ${ }^{29}$

In general, children with moderate-to-severe OI have delayed motor development as a result of a combination of factors including recurrent fractures, bone deformities, and increased joint laxity and pain. ${ }^{30,31}$ With the use of bisphosphonate therapy, fewer fractures are expected and this would result in lesser time of immobilization, more opportunity to develop motor milestones/function, muscle mass and bone strength. ${ }^{32}$ The resultant decrease in bone pain with treatment has been shown to independently cause increased muscle strength. ${ }^{33}$

Munns et al have detected an improvement in gross motor and mobility scores using the Pediatric Evaluation of Disability Inventory after early intravenous pamidronate treatment. $^{26}$ Similarly, Astrom et al showed that bisphosphonate treatment brought about earlier acquisition of motor milestones in their cohort of 11 infants. ${ }^{34}$

A more recently published article comparing patients who underwent intravenous pamidronate therapy to untreated historical controls showed that children with OI type III had earlier attainment of major motor milestones 'rolling from supine to prone and back', 'crawling and standing with support' and 'independent walking' but improvement did not reach significant levels with sitting with support. ${ }^{35}$
A similar response to bisphosphonate treatment was seen in OI Type $\mathrm{V}$ as in other OI types. ${ }^{36}$ Pamidronate therapy in the siblings resulted clinically to less pain and better stamina.

Although bisphosphonate therapy has its advantages, it cannot be used singly in the management of patients with OI. This has to be coupled with physiotherapy, occupational therapy and surgery to correct skeletal deformities. ${ }^{16,21,37}$ The sisters have been seen by pediatric orthopedic surgeons with plans of intramedullary rodding of the femur and tibia.

\section{Genetic Counseling}

The two families reported here show pedigree patterns consistent with autosomal dominant inheritance as expected of OI type V (Figures 5 and 6). The families have been counseled that the recurrence risk is of having another child with $\mathrm{OI}$ is $50 \%$ in every pregnancy. The children will have to be eventually educated about this especially when they reach reproductive age.

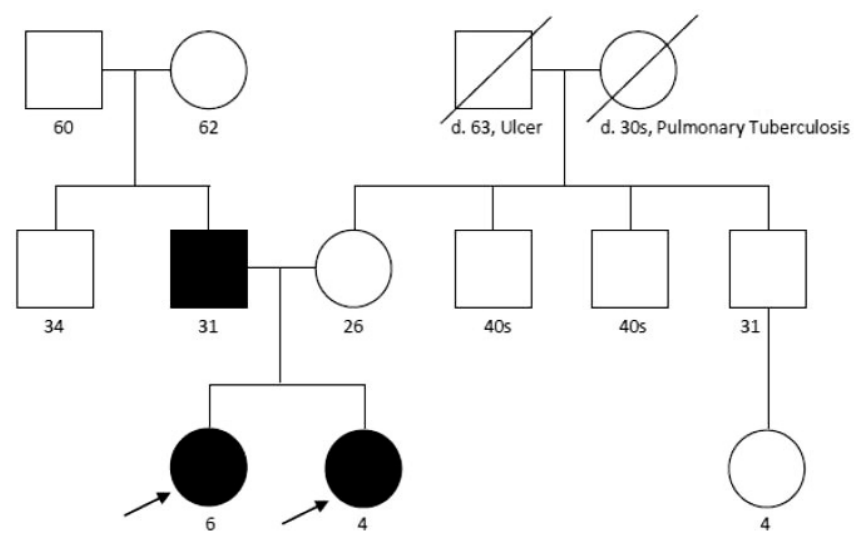

Figure 5. Pedigree of Family A.

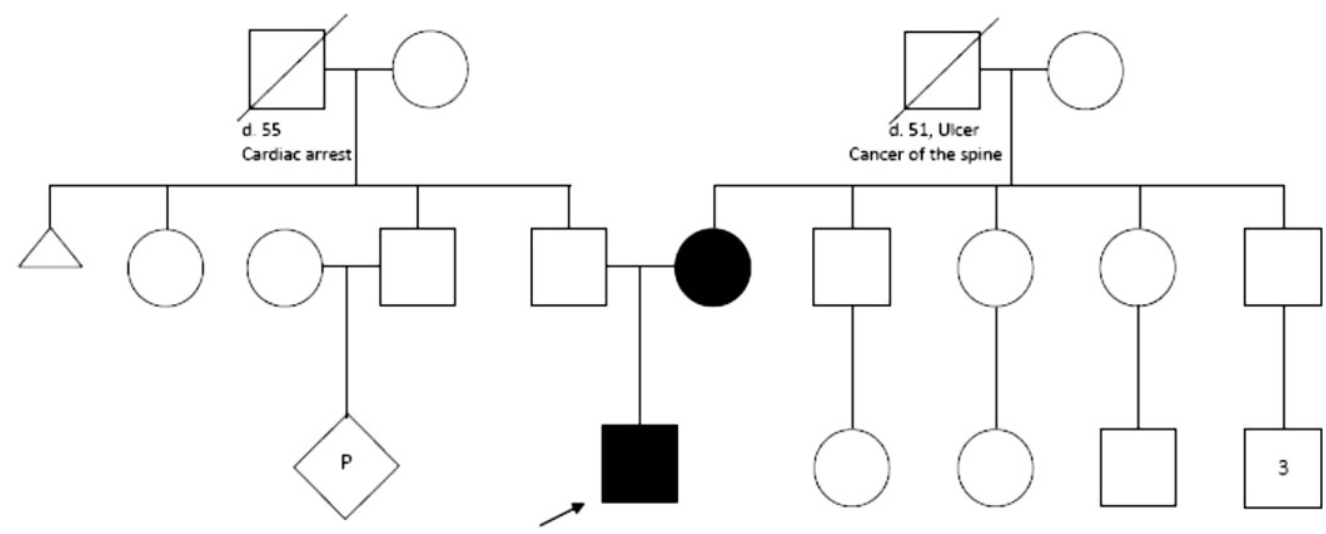

LEGEND:

Oltype V

Figure 6. Pedigree of Family B. 


\section{Conclusion}

In summary, we have provided detailed phenotypic information on OI type $\mathrm{V}$ among a series of Filipino patients. OI type $\mathrm{V}$ has to be distinguished from osteosarcoma so as not to subject patients into unnecessary treatment protocols which may prove harmful. We have also reviewed the current literature on OI type $\mathrm{V}$ from its clinical and radiologic presentation, the genetics of the disease, its management and the genetic counseling issues involved.

Diagnosis of OI type $\mathrm{V}$ can be made from its clinical features distinct from the other types of OI. Prevention of pathological fractures is the goal in all OI patients. With early diagnosis and early initiation of Pamidronate therapy, pathologic fractures and late bony deformities can be prevented thereby improving quality of life of these patients.

\section{Acknowledgment}

The authors thank Professor David Sillence for his invaluable input in the writing of this manuscript.

\section{References}

1. Van Dijk FS, Sillence DO. Osteogenesis Imperfecta: Clinical diagnosis, nomenclature and severity assessment. Am J Med Genet A. 2014; 164A (6):1470-81.

2. Balasubramanian M, Parker MJ, Dalton A, et al. Genotype-phenotype study in type V osteogenesis imperfecta. Clin Dysmorphol. 2013; 22 (3):93-101.

3. Sillence DO, Senn A, Danks DM. Genetic heterogeneity in osteogenesis imperfecta. J Med Genet. 1979; 16(2):101-16.

4. Forlino A, Cabral WA, Barnes AM, Marini JC. New perspectives on Osteogenesis imperfecta. Nat Rev Endocrinol. 2011; 7(9):540-57.

5. Glorieux FH, Rauch F, Plotkin H, et al. Type V osteogenesis imperfecta: a new form of brittle bone disease. J Bone Miner Res. 2000; 15(9):1650-8.

6. Marini JC, Forlino A, Cabral WA, et al. Consortium for osteogenesis imperfecta mutations in the helical domain of type 1 collagen: regions rich in lethal mutations align with collagen binding sites for integrins and proteoglycans. Hum Mutat. 2007; 28(3):209-21.

7. Semler O, Garbes L, Keupp K, et al. A mutation in the 5'-UTR of IFITM5 creates an in-frame start codon and causes autosomal-dominant osteogenesis imperfecta type $\mathrm{V}$ with hyperplastic callus. Am J Hum Genet. 2012; 91(2):349-57.

8. Cho TJ, Lee KE, Lee SK, et al. A single recurrent mutation in the $5^{\prime}$-UTR of IFITM5 causes osteogenesis imperfecta type V. Am J Hum Genet. 2012; 91(2):343-8.

9. Van Dijk FS, Zillikens MC, Micha D, et al. PLS3 mutations in X-Linked osteoporosis with fractures. N Engl J Med. 2013; 369(16):1529-36.

10. Van Dijk FS, Byers PH, Dalgleish R, et al. EMQN best practice guidelines for the laboratory diagnosis of osteogenesis imperfecta. Eur J Hum Genet. 2012; 20(1):11-9.

11. Rauch F, Moffatt P, Cheung M, et al. Osteogenesis imperfecta type V: marked phenotypic variability despite the presence of the IFITM5 c.14C $>$ T mutation in all patients. J Med Genet. 2013; 50(1):21-4.

12. Cheung MS, Glorieux FH, Rauch F. Natural history of hyperplastic callus formation in osteogenesis imperfecta type V. J Bone Miner Res. 2007; 22(8):1181-6.

13. Kim OH, Jin DK, Kosaki $\mathrm{K}$, et al. Osteogenesis imperfecta type V: Clinical and radiographic manifestations in mutation confirmed patients. Am J Med Genet. 2013; 161A(8):1972-9.

14. Arundel P, Offiah A, Bishop NJ. Evolution of the radiographic appearance of the metaphyses over the first year of life in type $\mathrm{V}$ osteogenesis imperfecta: clues to pathogenesis. J Bone Miner Res. 2011; 26(4):894-8.
15. Lazarus S, Moffat P, Duncan EL, Thomas GP. A brilliant breakthrough in OI type V. Osteoporos Int. 2014; 25(2):399-405.

16. Bishop N. Characterising and treating ostegenesis imperfecta. Early Hum Dev. 2010; 86(11):743-6.

17. Moffatt P, Gaumond MH, Salois P, et al. Bril: a novel bone-specific modulator of mineralization. J Bone Miner Res. 2008; 23(9):1497-508.

18. Hanagata $\mathrm{N}, \mathrm{Li} \mathrm{X}$, Morita $\mathrm{H}$, Takemura $\mathrm{T}$, Li J, Minowa $\mathrm{T}$. Characterization of the osteoblast specific transmembrane protein IFITM5 and analysis of IFITM5-deficient mice. J Bone Miner Metab. 2011; 29(3): $279-90$.

19. Lazarus S, McInerney-Leo AM, McKenzie FA, et al. The IFITM5 mutation c.-14C $>\mathrm{T}$ results in an elongated transcript expressed in human bone; and causes varying phenotypic severity of osteogenesis imperfecta type V. BMC Musculoskelet Disord; 2014;15:107

20. Glorieux FH. Osteogenesis Imperfecta. Best Pract Res Clin Rheumatol. 2008; 22 (1):85-100.

21. Monti E, Mottes M, Fraschini P, et al. Current and emerging treatments for the management of osteogenesis imperfecta. Ther Clin Risk Manag. 2010; 6: 367-81.

22. Glorieux FH, Bishop NJ, Plotkin H, Chabot G, Lanoue G, Travers R. Cyclic administration of pamidronate in children with severe osteogenesis imperfecta. N Engl J Med. 1998; 339(14): 947-52.

23. Rauch F, Plotkin H, Zeitlin L, Glorieux FH. Bone mass, size, and density in children and adolescents with osteogenesis imperfecta: effect of intravenous pamidronate therapy. J Bone Miner Res. 2003; 18(4): 610-4.

24. Land C, Rauch F, Munns CF, Sahebjam S, Glorieux FH. Vertebral morphometry in children and adolescents with osteogenesis imperfecta: effect of intravenous pamidronate treatment. Bone. 2006; 39(4):901-6.

25. Rauch F, Plotkin H, Travers R, Zeitlin L, Glorieux FH. Osteogenesis imperfecta types I, III and IV: effect of pamidronate therapy on bone and mineral metabolism. J Clin Endocrinol Metab. 2003; 88(3):986-92.

26. Munns CF, Rauch F, Travers R, Glorieux FH. Effects of intravenous pamidronate treatment in infants with osteogenesis imperfecta: clinical and histomorphometric outcome. J Bone Miner Res. 2005; 20(7):1235-43.

27. DiMeglio LA, Ford L, McClintock C, Peacock M. Intravenous pamidronate treatment of children under 36 months of age with osteogenesis imperfecta. Bone. 2004; 35(5):1038-45.

28. Plotkin H, Rauch F, Bishop NJ, et al. Pamidronate treatment of severe osteogenesis imperfecta in children under 3 years of age. J Clin Endocrinol Metab. 2000; 85(5):1846-50.

29. Alcausin MMB, de Dios JKL, Chiong MAD, Cavan BCV, David-Padilla C, Cutiongco-de la Paz EM. Intravenous pamidronate treatment in Filipino children with moderate to severe osteogenesis imperfecta. Acta Med Philipp. 2011; 45(4):35-9.

30. Engelbert RH, Uiterwaal CS, Gulmans VA, Pruijs HE, Helders PJ. Osteogenesis imperfecta: profiles of motor development as assessed by a postal questionnaire. Eur J Pediatr. 2000; 159(8):615-20.

31. Engelbert RH, Uiterwaal CS, Gulmans VA, Pruijs H, Helders PJ. Osteogenesis imperfecta in childhood: prognosis for walking. J Pediatr. 2000; 137(3):397-402.

32. Zeitlin L, Fassier F, Glorieux FH. Modern approach to children with osteogenesis imperfecta. J Pediatr Orthop B. 2003; 12(2):77-87.

33. Montpetit K, Plotkin H, Rauch F, Bilodeau N, Cloutier S, Rabzel M, et al. Rapid increase in grip force after start of pamidronate therapy in children and adolescents with severe osteogenesis imperfecta. Pediatrics. 2003; 111(5 Pt 1):e601-3.

34. Astrom $\mathrm{E}$, Jorulf $\mathrm{H}$, Soderhall $\mathrm{S}$. Intravenous pamidronate treatment of infants with severe osteogenesis imperfecta. Arch Dis Child. 2007; 92(4):332-8

35. Alcausin MB, Briody J, Pacey V, et al. Intravenous Pamidronate Treatment in Children with Moderate-to-Severe Osteogenesis Imperfecta Started under Three Years of Age. Horm Res Paediatr. 2013;79(6):333-40

36. Zeitlin L, Rauch F, Travers R, Munns C, Glorieux FH. The effect of cyclical intravenous pamidronate in children and adolescents with osteogenesis imperfecta type V. Bone. 2006; 38(1):13-20.

37. Astrom E, Soderhall S. Beneficial effect of long term intravenous bisphosphonate treatment of osteogenesis imperfecta. Arch Dis Child. 2002; 86(5):356-64 